\title{
ИНФРАСТРУКТУРНОЕ ОБЕСПЕЧЕНИЕ ТРАНСПОРТНО-ЛОГИСТИЧЕСКОЙ СИСТЕМЫ
}

\section{INFRASTRUCTURE SUPPORT FOR THE TRANSPORT AND LOGISTICS SYSTEM}

\section{S. Ilyukhina \\ D. Efimenko}

Summary. The article discusses the problems of justifying the economic efficiency of the transport and logistics system on the basis of the Transport Strategy of the Russian Federation for the period up to 2030, the issues of the need to create unified transport nodes for multimodal transport, revealed the dependence of the infrastructure of the node on the provided services of the logistics operator and the region of its activity. Special attention is paid to the distinction of business processes in the activities of logistics operators. Invention proposes to create transport and logistics bridges with accumulation of multimodal transport operator control function.

Keywords: transport hub, transport system, infrastructure support of the transport system, business processes, multimodal transportation, logistics operator.

\author{
Илюхина Светлана Сергеевна \\ К.т.н., дочент, ФГБОУ ВО Московский автомобильно- \\ дорожный государственный технический университет \\ «МАДИ» \\ sana18@mail.ru \\ Ефименко Дмитрий Борисович \\ Д.т.н., ФГБОУ ВО Московский автомобильно- \\ дорожный государственный технический университет \\ «МАДИ» \\ ed2002@mail.ru
}

Аннотация. В статье рассматриваются проблемы обоснования экономической эффективности транспортно-логистической системы на основе Транспортной стратегии Российской Федерации на период до 2030 года, вопросы необходимости создания единых транспортных узлов для обеспечения мультимодальных перевозок, выявлена зависимость инфраструктуры узла от предоставляемых услуг логистического оператора и региона его деятельности. Особое внимание уделено разграничению бизнес-процессов в деятельности логистических операторов. Предложено создание транспортно-логистических мостов с аккумулированием функции управления оператором мультимодальной перевозки.

Ключевые слова: транспортный узел, транспортная система, инфраструктурное обеспечение транспортной системы, бизнес-процессы, мультимодальные перевозки, логистический оператор.

затрагивались такими отечественными учеными как В.И. Сергеев, В.В. Щербаков, В.В. Дыбская, Л.Б. Миротин, А.В. Дмитриев, и зарубежными, такими как Р. Баллоу, Дж. Койл и других. Анализ источников показывает, что основным направлением исследования выступает модернизация логистической функции (транспортировки) за счет пересмотра основных логистических работ. Однако остаются мало освещенными вопросы создания и организации деятельности логистических центров.

Смешанные (мультимодальные) перевозки остаются наиболее сложными к использованию из-за разных подходов к управлению и принципов организации процессов на различных видах транспорта. Однако все они реализуются через правила логистики (7R) и коррелируются с основными правилами маркетинга (7P).

Проблема обоснования экономической эффективности транспортно-логистической системы состоит в двойственности материального потока [7]. Транспортная система рассматривает груз и транспортное средство как 
Таблица 1. Прогноз перевозок грузов и грузооборота по инновационному варианту развития транспортной системы России до 2030 года [1]

\begin{tabular}{|c|c|c|c|c|c|c|}
\hline & 2000 & 2006 & 2013 & 2015 & 2020 & 2030 \\
\hline Перевозки грузов -всего, млн. тонн & 10217,6 & 11821,3 & 12544,3 & 14823,9 & 16755,5 & 20679,4 \\
\hline В т.ч. транспорт общего пользования & 1749,6 & 2189,2 & 2348,1 & 2853,9 & 3315,5 & 4219,4 \\
\hline \multicolumn{7}{|l|}{ из всего: } \\
\hline 1. Автомобильный транспорт & 5878,0 & 6753,3 & 6955,0 & 8100,0 & 9260,0 & 12300,0 \\
\hline В т.ч. общего пользования & 550,0 & 712,9 & 709,1 & 830,0 & 1020,0 & 1550,0 \\
\hline 2. Железнодорожный транспорт (промышленный) & 3140,0 & 3591,7 & 3950,3 & 4700,0 & 5200,0 & 5710,0 \\
\hline 3 Морской транспорт & 35,4 & 25,4 & 35,8 & 85,0 & 140,0 & 252,0 \\
\hline 4. Внутренний водный транспорт & 116,8 & 139,2 & 160,1 & 179,2 & 203,0 & 262,4 \\
\hline 5. Воздушный транспорт & 0,55 & 0,64 & 1,1 & 1,7 & 2,5 & 5,0 \\
\hline Грузооборот - всего, млрд. т-км & 1745,9 & 2332,6 & 2784,0 & 3311,7 & 3899,3 & 4565,1 \\
\hline
\end{tabular}

независимые единицы материального потока, в логистической системе эти единицы взаимосвязаны.

В работе «Транспортная логистика» под общей редакцией Л.Б. Миротина приводится типология грузоперевозок, при которой обьектом исследования становится интермодальная единица [11]. Это дает возможность представить материальный поток как производную от совокупного движения транспорта системы и выявить обоснованность создания инфраструктурного обеспечения для транспортно-логистической системы смешанных грузоперевозок.

Инфраструктурное обеспечение напрямую связано с характеристиками транспортного узла, т.е. совокупности ресурсов в технологических процессах для обеспечения, координации и повышения эффективности грузоперевозок [11]. Транспортный узел является системой, состоящей из совокупности транспортных процессов и обеспечения их реализации в узлах взаиможействия видов транспорта [2]. Организационно-транспортные услуги, реализуемые в узле, способствуют маршрутизации транспортных потоков и выбору оптимальных способов доставки. Конечный перечень услуг зависит от инфраструктурного развития региона и согласованности технологии грузоперевозок. Сегодня многие компании стараются перейти на аутсортинг по основным вопросам складирования, перевозки, распределения, используя услуги 3PL-провайдеров. Для развития данного направления потребуется модернизация терминально-складских комплексов и подвижного состава. Особую конкуренцию будут создавать транснациональные корпорации и глобальные логистические операторы. Выход большего колличества российских компаний на рынок логистических провайдеров может быть осуществлен путем изменений административного и законодательного регулирования. Основным требованием к инфраструктуре в рамках транспортного узла остается развитая инже- нерная составляющая с коммунально-складским хозяйством, категорированным по мировым стандартам. Это прежде всего выражается в подборе универсального подьемно-транспортного оборудования, использовании современных технологических систем транспортировки грузов и способности предоставлять полный набор логистических услуг.

Транспортная стратегия РФ ставит задачу комплексного развития инфраструктуры. В данном документе делается прогноз развития по инновационному варианту (см табл 1).

Основные положения Транспортной стратегии предполагают:

- совершенствование инфраструктуры отрасли и создание единого комплекса;

- совершенствование технологического обеспечения транспортной отрасли;

- использование инновационных организационно-правовых моделей при осуществлении федеральных и региональных проектов совершенствования транспортной инфраструктуры при осуществлении единого договора подряда.

- повышение темпов развития инфраструктуры транспортной системы путем использования частного капитала, сокращения издержек на строительство и эксплуатацию объектов транспортной системы, совершенствования инфраструктуры транспортной системы.

Таким образом, данные задачи должны решаться через практическое построение варианта транспортной цепи с учетом критерия эффективности, который отражает интересы заказчика: минимизация затрат на транспортировку, оптимизация временных интервалов доставки (транзита), максимальная безопасность и надежность; и интересы исполнителя, которые характеризуются прежде всего требованиями минимиза- 
ции маршрутных расстояний и максимальной загрузки транспортного средства.

Инфраструктура транспортного узла зависит от количества видов транспорта, который в нем используется (максимально 6 видов). Число комбинаций типов транспортного узла рассчитывается как число состояний видов транспорта из 6 возможных с пределом изменений от 2 до 6 (случай с 1 не учитываем, т.к. данное состояние определяет юнимодальную перевозку). Данное предположение возможно из того, что система «... состоит из подсистем отдельных видов транспорта, которые в свою очередь имеют подсистемы низших классов. Так, для железнодорожного узла основными устройствами служат главные пути и станции. Для узла автомобильного транспорта таковыми являются автомобильные дороги, городские улицы, станции технического обслуживания, грузовые пункты погрузки-выгрузки, вокзалы. В узле, базирующемся на морском и речном портах, элементами общего назначения являются акватория порта, подходные каналы, грузовые и пассажирские причалы соответственно со складами и вокзалами. К основным элементам воздушного транспортного узла относятся аэродромы, аэровокзалы и терминалы» [12]. Можно сделать вывод, что подсистемы низшего уровня могут быть представлены как инфраструктурные подсистемы транспортной системы или выступать ее элементами. Суммарное число комбинаций (С 62=15; с63 = 20; С64 = 15; $C 56=6$; $C 66=1)$ будет равно 57. Однако на практике данная формализация не применима, т.к. существуют не сочетаемые виды транспорта. Логичным будет учесть специализацию отдельных видов транспорта, стандартизацию грузовых мест и дополнительные требования к грузу. Наиболее часто используемые варианты - это «железнодорожно-автомобильный», «железнодорожно-морской», «автомобильно-морской», «автомобильно-авиационный». Однако, большое сочетание видов транспорта наталкивает на мысль о возможности формирования транспортно-технологических мостов. Например, функционирование воздушного моста при водно-воздушной перевозке по маршруту Дальний Восток - Европа по воздушным коридорам территории Канады и США. Можно рассмотреть вариант, при котором используется маршрут перевозки через Тихий океан. В этом случае, груз следует контейнером до побережья США, где впоследствии с помощью автомобильного транспорта доставляется в аэропорт транзита на территории США и только потом происходит авиадоставка в города Европы согласно запланированного маршрута.

В России на сегодняшний момент нет развитых транспортно-технологических мостов. На основании статистических данных о грузопотоке различными видами транспорта можно предположить необходимость создания мостов железнодорожного транспорта. К со- жалению, созданные узлы во Владивостоке, Мурманске, Новороссийске, Санкт-Петербурге, Калининграде не обеспечивают синхронизацию транспортных потоков.

Проблемы данных узлов однотипны: недостаток складских помещений и погрузочно-выгрузных площадок, отсутствие тарифной политики, зависимость от погодных условий, отсутствие синхронизации между участниками процесса: грузоотправитель - перевозчик - грузополучатель. Основной проблемой является отсутствие единой информационной среды для обьектов транспортной инфраструктуры.

С 2014 года таможенными органами РФ реализуется проект «Портал Морской порт», который обеспечивает взаимодействие участников ВЭД, транспортников и таможенные органы по вопросам контроля и осуществления таможенных операций с товарами, пришедшими морским видом транспорта. Далее в логистической цепочке идет переключение на железнодорожный транспорт и участник ВЭД контактирует (чаще всего с ОАО «Российские железные дороги») уже в совершенно другой информационной системе. Перечисленные выше транспортные узлы можно считать за опорные для формирования перечня услуг логистического оператора в зоне узла. Эффективность деятельности будет достигнута при делегировании функции координации процессов участников мультимодальной перевозки единственной компании. Все технологические функции должны быть регламентированы на основании стандарта ИСО-9002 «Системы менеджмента качества» [14].

Реализация данного предложения требует создания алгоритмического инструментария и методологического обеспечения принятия решения оператора мультимодальной перевозки в связи с функциональными особенностями: определение класса транспорта; подбор транспортной организации; составление цепей поставки; внедрение логистической схемы доставки товаров; выявление необходимых дополнительных услуг и др.

Предлагается использовать двухуровневую классификацию бизнес-процессов.

1-й уровень будет закреплен за транспортировкой и будет реализовывать такие бизнес-процессы, как:

- формирование заказа

- консолидация заявок;

- подбор транспортной компании;

- экспедиторские услуги;

- бухгалтерское сопровождение;

- обеспечение соблюдения таможенного законодательства;

- деятельность в области страхования груза; 
- непосредственная транспортировка и др

2-й уровень будет обеспечивать реализацию складских функций и управление складом:

- размещение товаров на ответственное хранение;

- контроль сохранности грузов;

- погрузо-разгрузочные работы и обработка товара (палетирование, идентификация);

- документационное сопровождение движения товара на складе и его выпуск;

- финансовые механизмы реализации складской деятельности и т.д. и др.
Уровень обеспечивающих подсистем должен реализовывать бизнес-процессы по эксплуатации подвижного состава, управления складским оборудованием и содействовать сквозной информатизации всех бизнес-процессов.

Планируемый эффект модернизации инфраструктурного обеспечения транспортной системы связан с процедурой унификации бизнес-процессов и проектированием алгоритмической системы управления транспортным узлом при передаче функций контроля процесса транспортировки единому логистическому оператору.

\section{ЛИТЕРАТУРА}

1. Транспортная стратегия Российской Федерации на период до 2030 года: Утв. распоряжением Правительства РФ от 22 ноября 2008 г. № 17-34-р (с изменениями) [Электронный ресурс]. URL: https://www.mintrans.ru/ministry/targets/187/191/documents (дата обращения: 11.03.2020).

2. Информационный ресурс «Транспорт, Логистика, Перевозки» URL: http://logistica-transportnaya.narod.ru > . . i-transportnye... (дата обращения: 09 февраля 2020)

3. Дмитриев А. В. Логистическая координация транспортно-логистической деятельности. СПб.: Изд-во СПбГЭУ, 2016. 155 с.

4. Кокин А.С., Левиков Г. А. Транспортно-экспедиторские услуги при международной перевозке грузов. М.: Инфотропик Медиа, 2011. 576 с.

5. Логистика. Полный курс МВА / В. В. Дыбская, В. И. Сергеев. М.: ИНФРАМ, 2008. 944 с.

6. Логистика и управление цепями поставок: учебник для академического бакалавриата под ред. В. В. Щербакова. М.: Юрайт, 2015. С. $442-443$.

7. Першин И. В. Структурно-содержательный подход к управлению транспортными потоками в логистике // Логистика: современные тенденции развития: Материалы XIV Междунар. науч.-практ. конф. 9-10 апреля 2015 г. / отв. ред. В. С. Лукинский. СПб.: ГУМРФ им. адмирала С. 0. Макарова, 2015. С. $280-283$.

8. Прохоренко А.М., Истратов Р. А. Координирующая информационная система управления инфраструктурами транспортного узла // Вестник МГТУ. 2013. Том 16. № 1. С. 148-156.

9. Российский статистический ежегодник. 2018: Стат. сб. / Росстат. М., 2018.

10. Сергеев В.И., Федоренко А. И., Герами В.Д. Роль логистики в развитии транспортного комплекса Российской Федерации: в разрезе корректировки транспортной стратегии Российской Федерации на период до 2030 года [Электронный ресурc]. URL: http:// Iscm.ru/index.php/ru/po-godam/item/1181 (дата 06ращения: 11.02.2020).

11. Транспортная логистика: учебник для транспортных вузов / под общ. ред. Л. Б. Миротина. М.: Изд-во «Экзамен», 2002.

12. Федоров Л.С., Персианов В.А., Мухаметдинов И. Б. Общий курс. транспортной логистики: учебное пособие / под общ. ред. Л.С. Федорова. М.: КНОРуС, 2011. C. 120.

13. Центральная база данных Федеральной службы государственной статистики // URL: http://cbsd.gks.ru (дата обращения: 11.02.2020).

14. Консультант ГОСТ Р 57189-2016/ISO/TS9002:2016. Национальный стандарт Российской Федерации. Системы менеджмента качества. Руководство по применению ИСО 9001:2015 (IS0/TS9002:2016, IDT)» (утв. Приказом Росстандарта от 25.10.2016 N1499-CT) http://www.consultant.ru/document/cons_doc_ LAW_216185/ (дата обращения: 10.03.2020) 